Вследствие внедрения энергосберегающих мероприятий снизятся затраты энергии на поддержание микроклимата в зданиях и в результате высвободятся энергогенерирующие мощности. Это в свою очередь позволит обеспечить энергопотребление возводимых зданий без затрат на ввод в эксплуатацию новых мощностей.

Необходима разработка и утверждение на государственном уровне методики технико-экономической оценки эффективности внедрения энергосберегающих мероприятий, учитывающей экономический эффект от снижения потребности во вводе в строй новых энергогенерирующих мощностей и оценку экологического эффекта от снижения вредных выбросов в атмосферу.

1. Крупнов, Б.А. Об энергоэффективности и экономии тепловой энергии в зданиях различного назначения // Вестник МГСУ. - 2011. - № 3-1. - С. 411-414.

2. Табунщиков, Ю.А., Ливчак, В.И. Пути повышения энергоэффективности эксплуатируемых зданий / Ю.А. Табунщиков, В.И. Ливчак, В.Г. Гагарин, Н.В. Шилкин // АВОК. - 2009. - № 5.

3. СНиП 11-3-79*. Строительная теплотехника. 1998.

4. СНиП 23-02-2003. Тепловая защита зданий.

5. СНиП 41-01-2003. Отопление, вентиляция и кондиционирование.

6. Никитин, С.Н., Шилкин, Н.В. Поквартирные системы отопления // АВОК. - 2011. - № 2.

УДК 534

Артюшевская Екатерина Юрьевна

Амурский государственный университет

г. Благовещенск, Россия

E-mail: kateona2006@yandex.ru

Artyushevskaya Ekaterina Yurievna

Amur State University

Blagoveshchensk, Russia

E-mail: kateona2006@yandex.ru

Хондошко Юлия Владимировна

Амурский государственный университет

г. Благовещенск, Россия

E-mail: amur-ka_847@mail.ru

Khondoshko Yulia Vladimirovna

Amur State University

Blagoveshchensk, Russia

E-mail: amur-ka847@mail.ru

\author{
ОЦЕНКА ЭФФЕКТИВНОСТИ ПРИМЕНЕНИЯ МЕТОДА \\ АКУСТИЧЕСКОЙ ТОМОГРАФИИ ДЛЯ ДИАГНОСТИКИ ТЕПЛОВЫХ СЕТЕЙ
}

\title{
EVALUATING THE EFFECTIVENESS OF THE METHOD ACOUSTIC TOMOGRAPHY IN THE DIAGNOSIS OF THERMAL NETWORK
}

Аннотация. Анализируется эффективность применения метода акустической диагностики тепловых сетей. В связи с высокими затратами на проведение ремонтно-восстановительных мероприятий возникает необходимость в научных разработках, направленных на совершенствование методов и средств оценки технического состояния тепловых сетей. В ходе 
сравнительного анализа метода акустической томографии с бесконтактным магнитометрическим методом определены уровни точности.

Abstract. The article analyzes the effectiveness of the method of acoustic diagnostics of heat networks. Due to the high costs of carrying out repair and restoration activities, there is a need for scientific developments aimed at improving methods and tools for assessing the technical condition of heat networks. In the course of a comparative analysis of the acoustic tomography method with the noncontact magnetometric method, the accuracy levels were determined.

Ключевые слова: акустическая томография, тепловые сети, трубопровод, теплоснабжение, диагностика, коррозия, повреждения, толщинометрия, методы диагностики.

Key words: acoustic tomography, thermal networks, pipelines, heat supply, diagnostics, corrosion, damage, thickness measurement, diagnostic methods.

\section{DOI: 10/22250/jasu.9}

Стремление к повышению энергетической эффективности и надежности систем теплоснабжения требует обновления основных производственных фондов и снижения затрат на проведение ремонтно-восстановительных работ. В условиях дефицита финансовых средств при высоком росте затрат на ремонтно-техническое обслуживание, закупку запасных частей, монтажных и аварийновосстановительных работ необходимы новые технологии технического обслуживания. Особенно актуальными становятся научные разработки, направленные на совершенствование методов и средств оценки технического состояния теплоэнергетического оборудования.

В настоящее время сокращение времени на обнаружение и устранение дефекта трубопровода является важной задачей, ведь перерыв в теплоснабжении не только отрицательно сказывается на комфорте потребителей, но и затрудняет движение транспорта и пешеходов, увеличивает затраты, связанные с объемом земляных работ и последующим восстановлением нарушенного ландшафта местности.

Места повреждений участков тепловых сетей подземной прокладки, которые выявляются в процессе испытаний трубопроводов на плотность, чаще всего обнаруживаются на второй или третьей шурфовке грунта. Для реализации шурфовок применяется тяжелая техника, каждый час работы которой обходится недешево. Восстановление строительных конструкций, герметизация канала, обратная засыпка, а также восстановление благоустройства территории сильно затратны в финансовом плане. В крупных городах такие мероприятия обходятся в десятки миллионов рублей.

Предприятиям, которые эксплуатируют сотни километров подземных трубопроводов и строительных конструкций, для их качественного технического обслуживания необходимо систематически наблюдать за оборудованием, своевременно предотвращать возможные повреждения, точно определять место повреждения по длине канала с целью его оперативного устранения, прогнозировать время и место возможного возникновения повреждения.

Для качественной диагностики повреждений трубопроводов используют различные устройства и приборы, но особую ценность имеют ресурсосберегающие технологии, позволяющие сокращать время выполнения работ и экономить трудовые ресурсы.

На сегодня в России наиболее популярными методами диагностики трубопроводов тепловых сетей подземной прокладки являются $[1,2]$ : испытания участков трубопроводов давлением не менее 1,25 от рабочего; акустический метод; метод магнитометрии с помощью внутритрубного дефектоскопа, определяющего сплошность металла; метод шурфовок грунта со вскрытием канала инженерной сети. 
Применение метода акустической томографии трубопроводов и ранжирование участков, выводимых в перекладку по результатам диагностики, позволяет снизить количество утечек при снижении объемов перекладок. Снижению количества утечек способствует также информация об интервалах, ранжируемых как участки наихудшего состояния, и проведение на них предупредительных ремонтных работ. Высокая точность обнаружения мест повреждения трубопроводов значительно сокращает затраты времени на обнаружение порывов тепловых сетей, уменьшает затраты на их устранение. Каждая утечка, точно обнаруженная с помощью течеискателя, позволяет избежать в среднем двух шурфовок. Проведение инженерной диагностики в зимний период дает возможность более рационально подготовиться к ремонтно-восстановительным работам в летний период.



Puc. 1. Акустический томограф «Каскад-3».

При использовании метода акустической томографии широко применяются синхронные регистраторы акустических сигналов «Каскад» (рис. 1). Эти приборы разработаны на моделях синхронных акустических регистраторов, но модернизированы современной элементной базой.

Основными достоинствами приборов являются компактность и удобство в эксплуатации: два выносных блока, логичная последовательность программирования, большая память для хранения записей, долгий период автономной работы без подзарядки аккумуляторной батареи; наличие механизмов защиты от посторонних акустических помех, - таких, как «городской шум».

Одной из главных причин разрушения трубопроводов и образования течей является наличие зон повышенных механических напряжений, в которых наиболее интенсивно протекают процессы коррозии, ползучести и усталости.

Процесс диагностики с помощью акустической томографии заключается в фиксировании акустических сигналов, распространяющихся по трубе. Затем сигналы подвергаются фильтрации, и с помощью корреляционного анализа определяются местоположения источников повреждений по всей длине проверяемого участка, а также оценка их уровня. Метод акустической томографии помогает определить зоны аномалий по совокупности уровня утонения и напряжения стенки трубопровода.

Компания «ИПК Шерна» провела исследование состояния трубопроводов на основе метода акустической томографии. Основными этапами анализа являлись: оценка результатов ультразвуковой толщинометрии в зонах повреждений, выявленных с помощью метода акустической томографии; сравнение результатов диагностики методом акустической томографии с местами, где произошли аварии; сравнение результатов диагностики с данными, полученными при использовании магнитометрического метода диагностики.

Проводился анализ участков, где в ходе акустической томографии были выявлены критические дефекты. В ходе дополнительного визуально-измерительного контроля в $65 \%$ случаев результаты подтверждались данными УЗК-толщинометрии. Были зафиксированы утонения, которые распространились на значительной площади и сопровождались большим слоем коррозионных отложений, в остальных случаях, - как правило, в зонах дефектов по методу акустической томографии при помощи магнитометрического метода диагностики. Фиксировались изменения магнитного поля, подтверждающие наличие напряженно деформированного состояния металла трубопровода. Соответственно при помощи метода акустической томографии можно определить утонения стенок трубопроводов и предотвратить возможность аварии.

Для проверки данных на большинстве участков параллельно диагностике методом акустической томографии проводилась диагностика бесконтактным магнитометрическим методом. Результаты подвергались анализу и сравнению с фактическим состоянием трубопроводов. 
Наличие дефектов, выявленных в штатном режиме обработки акустической томографией, подтверждались результатами бесконтактного магнитометрического метода в 75\% случаев. Итоговая оценка критичности дефектов показала совпадение результатов обоих методов в $57 \%$ случаев. Более точная оценка методом акустической томографии получалась в $26 \%$ случаев, бесконтактным магнитометрическим методом была точнее в $17 \%$ случаев.

Метод акустической томографии демонстрирует высокие результаты с учетом общих факторов эксплуатации трубопроводов тепловых сетей. Применение в качестве дополнительной диагностики бесконтактного магнитометрического метода повышает качество получаемых результатов.

Полагаясь на результаты, полученные с помощью данных методов диагностики, можно применять локальные контактные методы неразрушающего контроля для более точной диагностики состояния трубопровода и оценки критических участков.

Совместное использование двух методов диагностики позволяет повысить надежность функционирования тепловых сетей. Быстрее обнаруживаются дефекты трубопроводов, а процесс технической диагностики становится более выгодным в финансовом плане.

1. Вакатов, А.В., Буклов, А.Е. Опыт инженерной диагностики тепловых сетей г. Тольятти // Новости теплоснабжения. - 2006. - № 9 (73).

2. Звягинцев, М.Ю. Опыт диагностики трубопроводов тепловых сетей методом акустической томографии в сочетании с бесконтактным магнитометрическим методом // Новости теплоснабжения. - 2012. - № 3 (139).

3. Фоминых, К.С. Применение метода акустической диагностики тепловой сети // Вестник науки и образования - 2019. - № 3-2 (57). - С. 15-18.

4. Соколов, Е.Я. Теплофикация и тепловые сети: учебник для вузов. - Изд. 7-е, стер. - М.: Изд-во МЭИ, 2001. $-472 \mathrm{c}$

5. Лепеш, Г.В. Диагностика и комплексное обслуживание инженерно-технических систем и оборудования зданий и сооружений // Технико-технологические проблемы сервиса. - 2016. - № 1 (35). - С. 6-16.

6. Лепеш, Г.В. Современные методы и средства диагностики оборудования инженерных систем зданий и сооружений // Технико-технологические проблемы сервиса. - 2015. - № 4 (34). - С. 3-8.

7. Малая, Э.М., Сергеева, С.А. Энергосбережение как важный фактор развития инфраструктуры теплоснабжения // Вестник Саратовского гос. техн. ун-та. - 2004. - № 1 (5). - С. 64-75.

8. Деревяшкин, И.С., Медяков, А.А., Юсупов, Т.М., Осташенков, А.П. Разработка модели процесса внутренней коррозии трубопроводов тепловых сетей // Инженерный вестник Дона. - 2018. - № 3 (50). - С. 71. 